\title{
Economic Analysis of Solar Refrigeration and Desalination System
}

\author{
Xiaoman Zhang, Qin Shen, Shijun Zhu \\ School of Manufacturing, Hunan Railway Professional Technology College, Zhuzhou, China
}

\begin{abstract}
The physical model and mathematical model of solar refrigeration and desalination cogeneration system were established. The performance and economy of the system were analyzed by changing the three variables of refrigeration capacity, seawater desalination effects number and three different cities. The results show that increasing refrigeration capacity is conducive to improving freshwater production and increasing freshwater efficiency, but more auxiliary heat consumption is needed,the comprehensive effect is to shorten the recovery period. Increasing desalination efficiency is conducive to increasing freshwater production and freshwater efficiency, and the auxiliary heat consumption remains unchanged. The comprehensive effect is to shorten the recovery period. Solar energy is the main energy needed in the co-generation system of the three cities, and Shenzhen has the largest proportion of energy supply, which reaches $67.8 \%$. Compared with the solar refrigeration system, the recovery period of the cogeneration system can bu shortened by $18.1 \%$.
\end{abstract}

\section{Introduction}

With the rapid development of society and economy, freshwater resources are not only an economic problem, but also a social problem related to human survival and development. Nearly 400 of the more than 600 cities in China are short of water, especially in the developed coastal areas. Most coastal cities have less than 500 cubic meters of fresh water per person, which is lower than the international bottom line of 1000 cubic meters per person, while Dalian, Qingdao and other cities have less than 200 cubic meters per person of fresh water resources, which is in a serious water shortage situation[1].The development of seawater desalination technology will become an effective strategic way to solve the shortage of freshwater in China.

Solar absorption refrigeration technology uses solar energy collected by solar collector to drive absorption refrigeration system, which is the most widely used solar refrigeration model so far. Its main advantages are good seasonal adaptability, no harm to the environment, less moving parts of refrigeration units and low noise, so as to better improve the utilization rate and economy of solar energy system. As the refrigeration system inevitably has a large number of condensation heat directly discharged into the surrounding environment, resulting in energy waste. Solar refrigeration seawater desalination co-generation system is a new technology, which can desalinate seawater by recovering condensation heat and obtain certain fresh water benefits. There are few reports on the research of this technology [2-5], mainly focusing on the technical feasibility and energy saving research, and the above-mentioned scholars' research has not made in-depth analysis of the interaction of the system parameters. In this paper, the physical model and economic model of the combined system of solar absorption refrigeration and desalination with vacuum tube collector are established, and the characteristics of the new system are simulated and analyzed, which provides a reference for the operation of practical projects.

\section{System design}

The working principle of the solar refrigeration and desalination co-generation system (see Fig.1) is as follows: the solar radiation heat is collected by the vacuum tube collector for heating the circulating water, the circulating water reaches the generator through the water storage tank, and is pumped back to the water storage tank after the heat is released by the generator. After the absorbent dilute solution in the generator absorbs the heat of the circulating water, the refrigerant vapor generated in the generator is introduced into the first-effect evaporator of seawater desalination unit to heat exchanges with the feed seawater, and the feed seawater is evaporated into fresh water by multi-effect evaporation in the seawater desalination unit to realize the function of seawater desalination. After condensation and exothermic of heated steam in seawater desalination unit, the heated steam becomes condensate water and flows to evaporator through throttle valve. A refrigeration water pipeline is set in the evaporator to provide refrigeration water for cold recovery and realize refrigeration function.

\footnotetext{
* Corresponding author: 187333843@qq.com
} 
The seawater desalination system is a low temperature multi-effect evaporation system. It contains evaporators, flash chambers, and an condenser, as shown in Fig.2. The intake seawater is introduced into the condenser, where it absorbs the latent heat of the condensing vapour from the last effect. Part of the heated intake seawater is rejected back to the sea, known as the cooling seawater. The feed seawater is imported into the first effect evaporator. The brine is heated to its boiling temperature before a small portion of it is evaporated. The vapour produced in each effect is condensed in the next effect. The remaining part of brine is introduced into the next effect by the pressure difference between the successive effects, which can save a substantial pumping power. The processes of evaporation and condensation are repeated in successive effects.

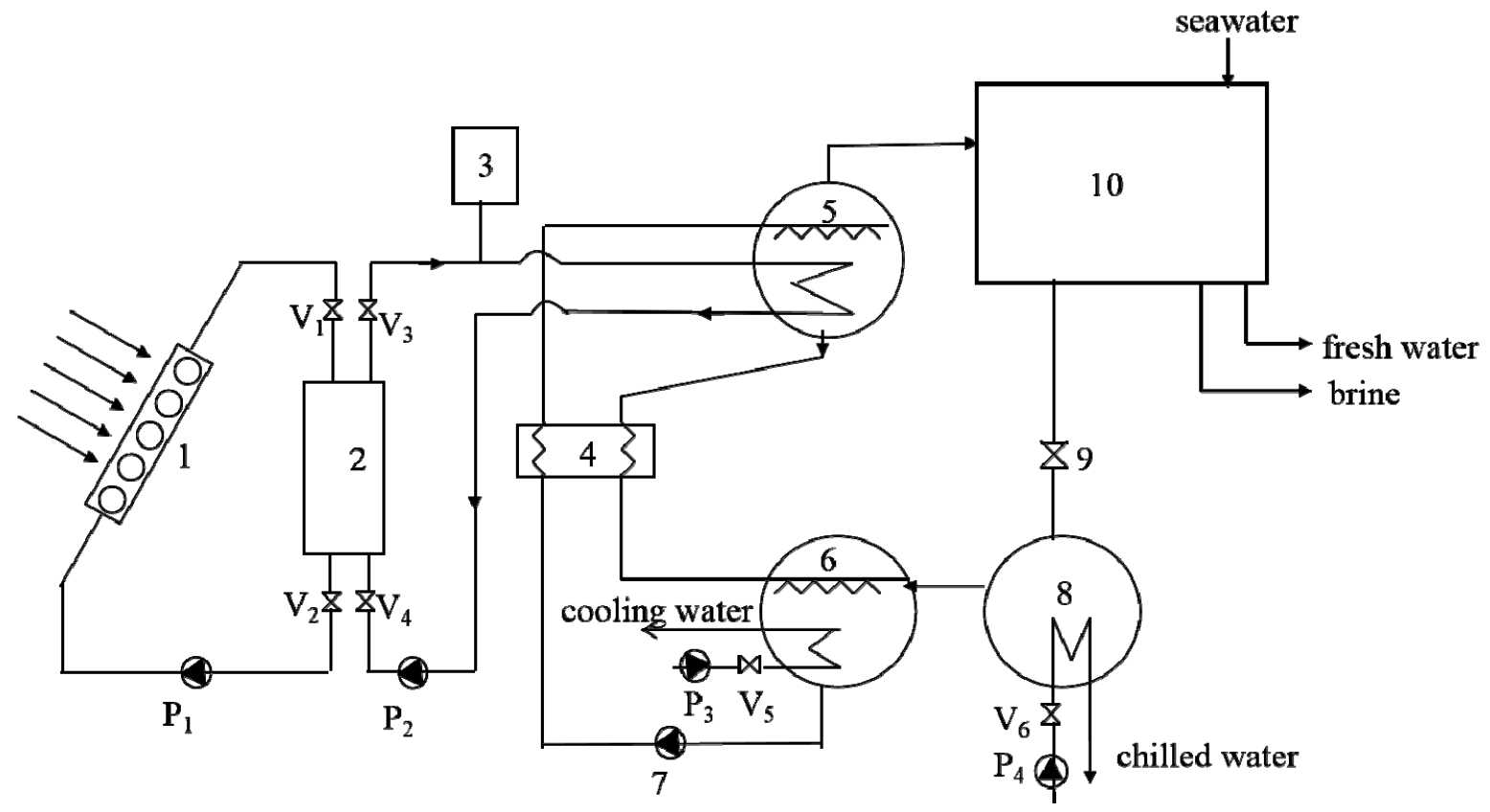

1-vacuum tube collector 2-water storage tank 3-auxiliary natural gas water heater 4-solution heat exchanger 5-generator 6- absorber 7-solution pump 8-evaporator 9-throttle valve 10-seawater desalination device $\mathrm{P}$-water pump V-valve

Fig. 1. Schematic of solar refrigeration and desalination system

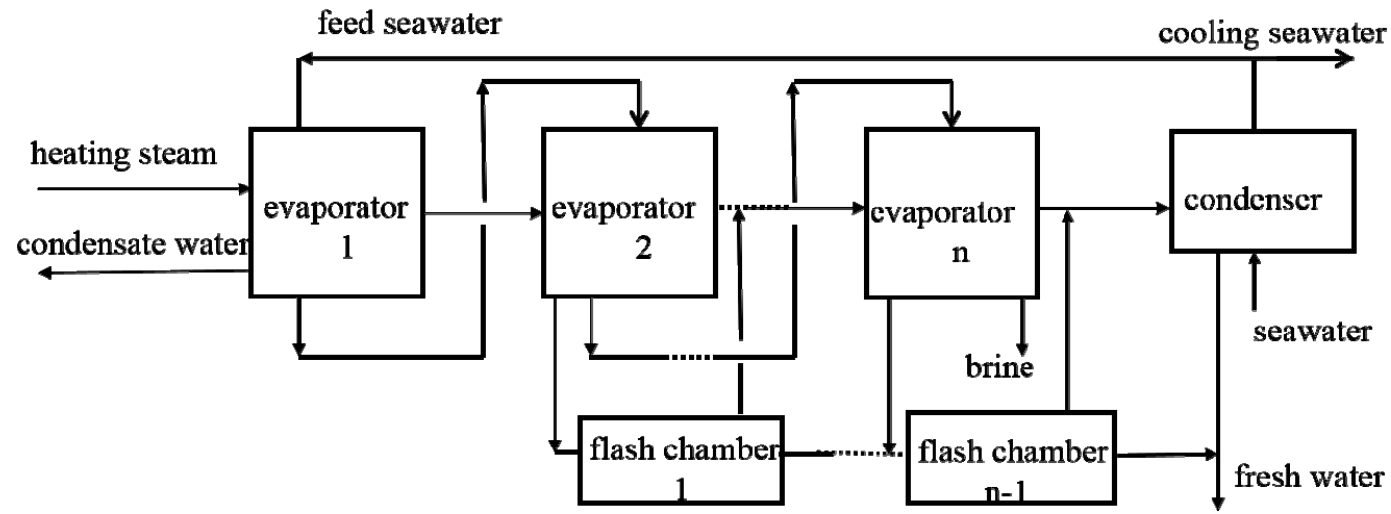

Fig. 2. Schematic of low temperature multi-effect evaporation desalination system

Because of the intermittent solar radiation, the auxiliary natural gas water heater is installed to ensure the stable operation of the system, and the start-up temperature is also set. There are two operation modes of co-generation system: when the daytime sunshine is sufficient, if the hot water outlet temperature of the water tank is higher than the start-up temperature, turn off the auxiliary natural gas water heater; when the daytime sunshine is insufficient or at night, if the hot water outlet temperature of the water tank is lower than the start-up temperature, turn on the auxiliary natural gas water heater to raise the water temperature to the start-up temperature. 


\section{System computing model}

Because of the seasonality of solar radiation, the amount of solar radiation varies from month to day.The concept of "monthly average day" is introduced to simplify the calculation, that is, the amount of solar radiation calculated on a certain day is used as the daily average of that month[6]. The mathematical models of absorption refrigeration and seawater desalination co-generation system are presented in reference [7], the mathematical model is solved by programming in MATLAB language, the flow chart is shown in Fig.3. The author only introduces the economic mathematical model.

\subsection{Initial investment}

Initial investment mainly includes initial investment of solar absorption refrigeration system and seawater desalination unit.

\subsubsection{Solar absorption refrigeration system}

Initial investment of solar absorption refrigeration system is obtained through comprehensive consideration of online inquiry and literature [8-9], as shown in Table 1 .

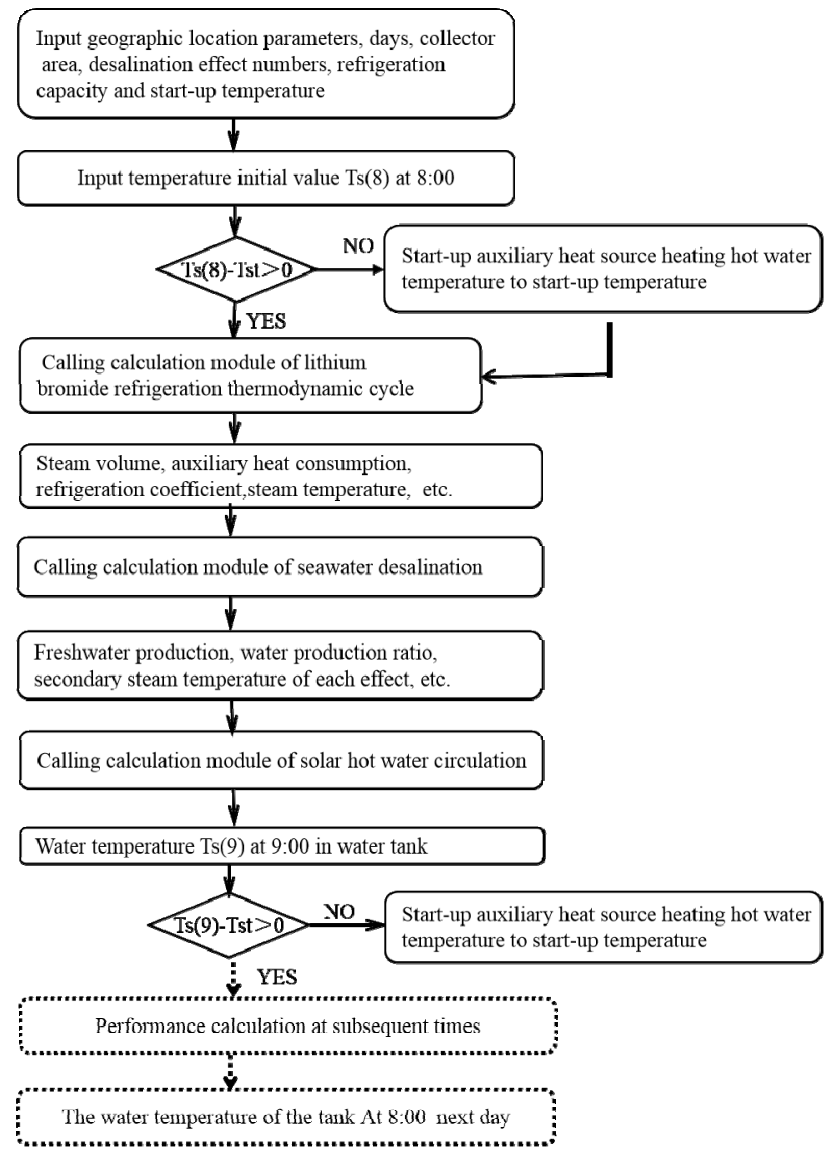

Fig.3. Solution procedure of solar refrigeration and desalination system

Table 1. Basic calculation parameters of initial investment in solar refrigeration system

\begin{tabular}{c|c|c|c}
\hline parameters & $U_{\text {col }}$ & $U_{\text {tank }}$ & $U_{\mathrm{e}}$ \\
\hline value & $1800 ¥ / \mathrm{m}^{2}$ & $650 ¥ / \mathrm{m}^{3}$ & $800 ¥ / \mathrm{kW}$ \\
\hline \multicolumn{1}{c}{$C_{1 \cdot \text { cost }}=A_{\text {col }} \times U_{\text {col }}+V_{\text {tank }} \times U_{\text {tank }}+Q_{\mathrm{e}} \times U_{\mathrm{e}}$}
\end{tabular}

Where $A_{\text {col }}$ is the area of the vacuum tube collector, $\mathrm{m}^{2} ; U_{\text {col }}$ is the unit price of the vacuum tube collector, $¥ / \mathrm{m}^{2} ; V_{\text {tank }}$ is the volume of the hot water storage tank, $\mathrm{m}^{3} ; U_{\mathrm{tank}}$ is the unit price of the hot water storage tank, $¥ / \mathrm{m}^{3} ; Q_{\mathrm{e}}$ is the refrigeration capacity, $\mathrm{kW}$; and $U_{\mathrm{e}}$ is the unit price of the refrigeration unit, $¥ / \mathrm{kW}$.

\subsubsection{Seawater desalination unit [10]}

$$
C_{2 \cdot \text { cost }}=0.12 \times\left(6.67+0.287 \times A_{\mathrm{d}}\right) \times\left[\left(U_{\text {cop }}-620\right)+4400\right]
$$

Where $A_{\mathrm{d}}$ is the heat transfer area, $\mathrm{m}^{2}, U_{\text {cop }}$ is the brass material market price, $¥ / \mathrm{t}$.

\subsection{Operation and maintenance costs in refrigeration season}

\subsubsection{Operation cost}

The operating cost of the system mainly includes the cost of desalination water pump, solar circulating water pump and auxiliary natural gas [11] .

$$
\begin{gathered}
C_{3 \cdot \text { oper }}=U_{\text {gas }} \times V_{\text {gas }}+U_{\text {elec }} \times \mathrm{h} \times\left(P_{1}+P_{2}\right) \\
P_{1}=4.36+0.0965 \times M_{\mathrm{d}}-2.2 \times M_{\mathrm{d}}^{2} \times 10^{-6} \\
P_{2}=0.02691 \times\left(0.045 \times A_{\text {col }}\right)^{1.1}
\end{gathered}
$$

Where $U_{\text {elec }}$ is the electricity price, $¥ / \mathrm{kWh} ; h$ is the running time, hour; $U_{\text {gas }}$ is the natural gas price, $¥ / \mathrm{m}^{3}$; $V_{\text {gas }}$ is the gas consumption, $\mathrm{m}^{3} ; M_{\mathrm{d}}$ is the fresh water output, $\mathrm{t} / \mathrm{d} ; P_{1}$ is the desalination water pump power consumption, $\mathrm{kW} ; P_{2}$ is the solar circulating water pump power consumption, $\mathrm{kW}$.

\subsubsection{Maintenance cost}

The system maintenance cost is calculated according to a certain proportion of the initial investment of the equipment [12] .

$$
C_{4 \cdot \text { maintain }}=\varepsilon \times\left(C_{1 \cdot \operatorname{cost}}+C_{2 \cdot \operatorname{cost}}\right)
$$

Where $\varepsilon$ is the proportionality coefficient.

\subsection{Freshwater benefit in refrigeration season}

Coastal cities can use desalinated water to make up for the shortage of water resources. They can sell desalinated water at market price and obtain certain economic benefits[13].

$$
C_{5 \text { benefit }}=U_{\text {water }} \times M_{\mathrm{d}} \times D
$$

Where $U_{\text {water }}$ is the freshwater unit price, $¥ / \mathrm{t}, D$ is the days for refrigeration season 


\subsection{Recovery period}

$$
\begin{gathered}
N_{\text {year }}=\frac{C_{1 \cdot \text { cost }}+C_{2 \cdot \text { cost }}-C_{1}}{C_{2}-\left(C_{3 \cdot \text { oper }}+C_{4 \cdot \text { maintain }}\right)+C_{5 \cdot \text { benefit }}} \\
C_{1}=Q_{e} \times U_{e}+C_{2 \cdot \text { cost }} \\
C_{2}=U_{\text {elec }} \times \mathrm{h} \times P_{1}+U_{\text {gas }} \times V+\varepsilon \times C_{1}
\end{gathered}
$$

Where $V$ is the natural gas consumption in conventional energy co-generation system, $C_{1}$ is the initial investment in conventional energy co-generation system, $C_{2}$ is the operation and maintenance cost of conventional energy co-generation system in refrigeration season.

The solar refrigeration desalination co-generation system operates in summer under refrigeration conditions. The basic calculation parameters are shown in Table 2.

Table 2. Basic calculation parameters in solar refrigeration desalination co-generation system

\begin{tabular}{c|c|c|c|c|c|c}
\hline parameters & $h$ & $U_{\text {elec }}$ & $U_{\text {gas }}$ & $\varepsilon$ & $U_{\text {water }}$ & $D$ \\
\hline value & 2160 & 0.6 & 3 & 0.02 & 8 & 90 \\
\hline
\end{tabular}

\section{System performance and economic analysis}

The solar refrigeration desalination co-generation system operates under summer refrigeration conditions. The basic calculation parameters are as follows: the area of vacuum tube collector is $80 \mathrm{~m}^{2}$, the starting temperature of the system is $96^{\circ} \mathrm{C}$, the initial mass concentration of seawater is $3.13 \%$; the temperature of feed seawater is $20^{\circ} \mathrm{C}$, the temperature of chilled water supply is $7^{\circ} \mathrm{C}$, and the heat utilization rate of the equipment is 0.98 . With other parameters unchanged, the performance and economy of the system were analyzed by changing refrigeration capacity, desalination effect numbers and choosing three different cities.

\subsection{The influence of refrigerating capacity}

In Shenzhen, seawater desalination has 3 effects, with other parameters unchanged, Fig.4 analyzed the influence of refrigeration capacity from $10 \mathrm{~kW}$ to $25 \mathrm{~kW}$ on fresh water output, auxiliary heat consumption, freshwater benefit and system recovery period.

With the increase of refrigeration capacity, the output of fresh water and auxiliary heat consumption increase, the benefit of fresh water increases, and the recovery period shortens. The main reasons are: increasing refrigeration capacity, the initial investment of refrigeration desalination unit will increase, the auxiliary heat consumption will increase, but the refrigerant vapor flow of refrigeration system will increase, which is conducive to water production, freshwater benefits increase, so the comprehensive effect is shortening the recovery period.

\subsection{The influence of desalination effect numbers}

In Shenzhen, with other parameters unchanged, Fig.5 analyzed the desalination effect numbers from 3 to 6 effects on fresh water production, auxiliary heat consumption, initial investment and recovery period of the system with $25 \mathrm{~kW}$ refrigeration capacity unchanged.

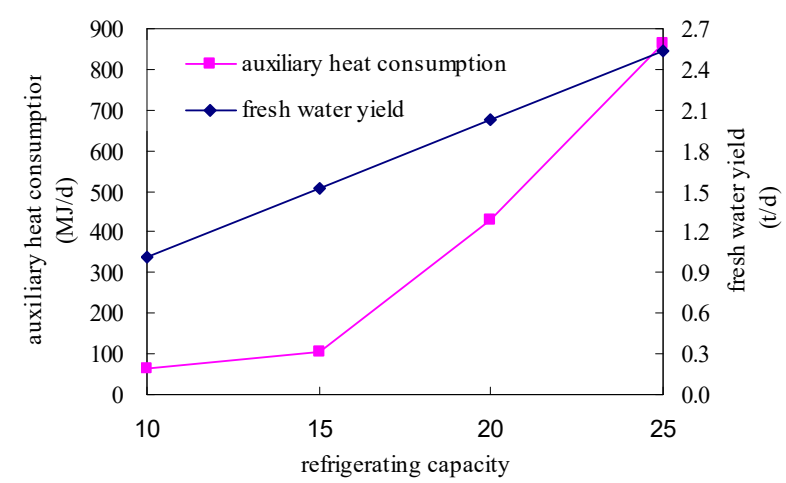

(a) Auxiliary heat consumption and fresh water yield

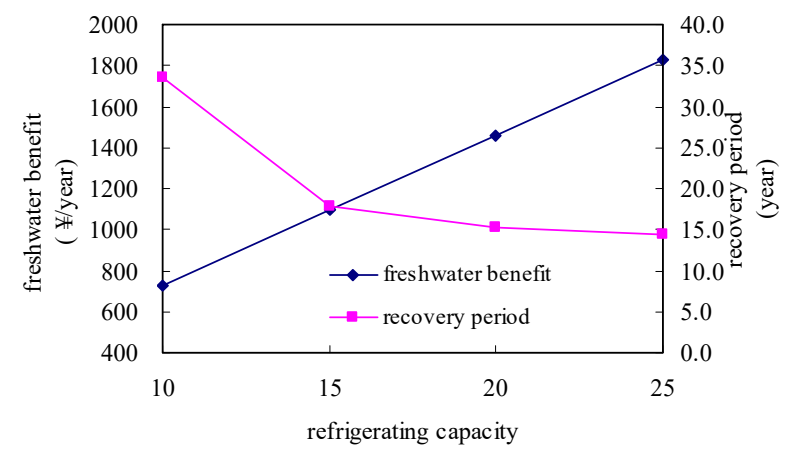

(b) Initial investment and payback period

Fig. 4 The influence of refrigeration capacity

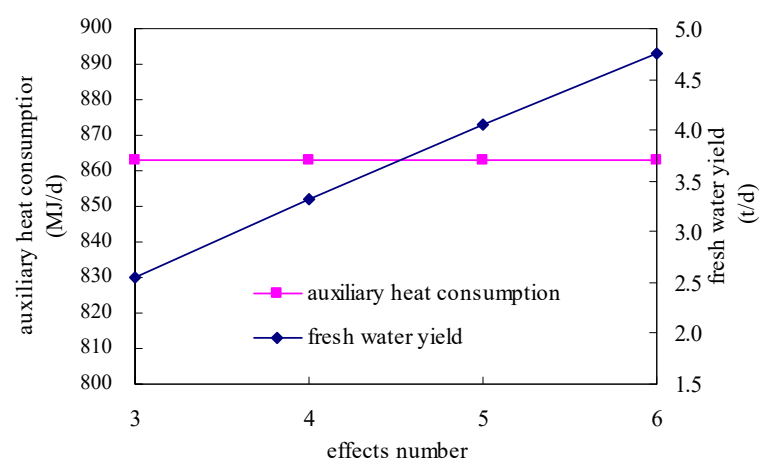

(a) Auxiliary heat consumption and fresh water yield 


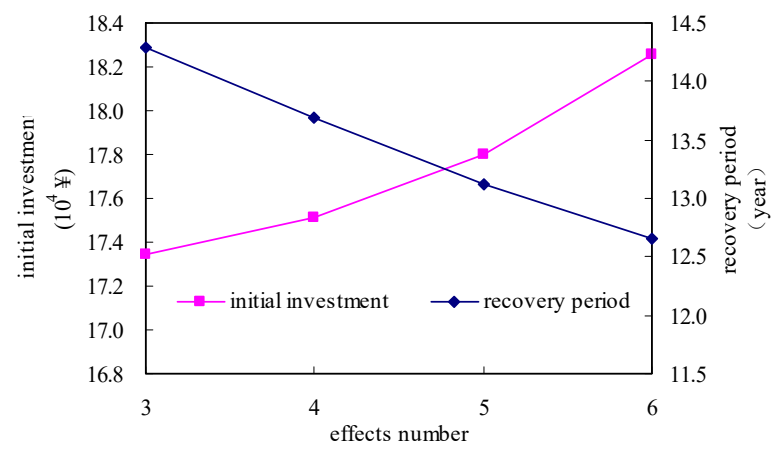

(b) Initial investment and payback period

Fig. 5 The influence of desalination effect numbers

With the increase of desalination efficiency, the output of fresh water increases, the benefit of fresh water increases, the auxiliary heat consumption remains unchanged, and the recovery period shortens. The main reasons are:

(1) With the increase of effect numbers, the number of reuse of secondary steam increases, and the output of fresh water increases, but at the same time, the heat transfer area of seawater desalination unit increases.

(2) Because the desalination unit is used to recover the waste heat of the refrigeration system, it will not affect the performance of the solar refrigeration system, so the auxiliary heat source remains unchanged.

(3) Increasing heat transfer area of seawater desalination unit will lead to increase initial investment of the system and freshwater production, so the comprehensive effect of both is shortening recovery period.

\subsection{Comparison of three cities}

For the same co-generation system, the refrigeration capacity is $25 \mathrm{~kW}$ and the desalination effect numbers is 3 . With the same other parameters, the three cities of Dalian, Shanghai and Shenzhen are compared, and compared with the solar refrigeration system.

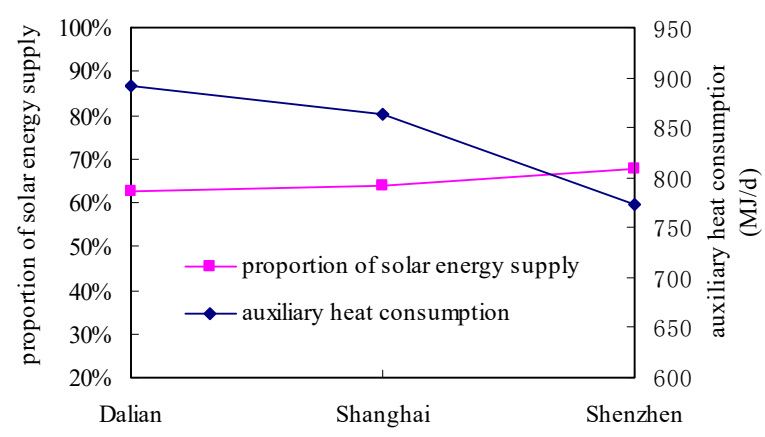

Fig.6 Comparison of three cities

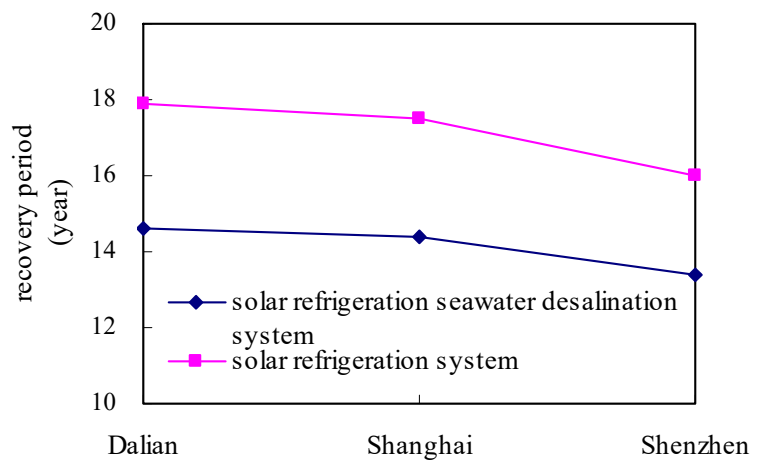

Fig. 7 Recovery period of two system

From Fig.6, we can see that solar energy is the main energy needed in the co-generation system of the three cities. Solar energy collection is inversely related to auxiliary heat consumption. Shenzhen has the largest proportion of energy supply, which reaches $67.8 \%$, Dalian has the smallest proportion of energy supply; Dalian has the largest auxiliary heat consumption and Shenzhen has the smallest proportion; from Fig.7, we can see that in the calculation range of this paper, Compared with solar energy refrigeration system, the recovery period of co-generation system can be shortened by $18.1 \%$.

\section{Conclusion}

(1) For the same city, with the increase of refrigeration capacity, freshwater production and auxiliary heat consumption increase, freshwater benefit increases and recovery period shortens; with the increase of desalination efficiency, freshwater production increases, freshwater benefit increases, auxiliary heat consumption does not change; recovery period shortens.

(2) Solar energy is the main energy needed in the cogeneration system of the three cities, Shenzhen has the largest proportion of energy supply, which reaches $67.8 \%$. Compared with the solar refrigeration system, the recovery period of the co-generation system can be shortened by $18.1 \%$.

* Foundation projects: Hunan Provincial Education Department funded scientific research projects (16C1043)

\section{References}

[1] Y.Y.Ma. Management countermeasures research on promoting the development of seawater desalination industry in Tianjin,Tianjin University of Finance and Economics,China, (2017).

[2] Y.q.Wang. Noam Lior. Proposal and analysis of a high-efficiency combined desalination and refrigeration system based the $\mathrm{LiBr}-\mathrm{H} 2 \mathrm{O}$ absorption cycle-Part 1: system configuration and mathematical model. Energy Conversion and Management,52(1):220-227,(2011). 
[3] Y.q.Wang. Noam Lior. Proposal and analysis of a high-efficiency combined desalination and refrigeration system based the $\mathrm{LiBr}-\mathrm{H} 2 \mathrm{O}$ absorption cycle-Part 2: Thermal performance analysis and discussions. Energy Conversion and Management, 52(1):228-235,(2011).

[4] Janette Hogerwaard, Ibrahim Dincer, Greg F. Naterer.Solar energy based integrated system for power generation, refrigeration and desalination. Applied Thermal Engineering, 121:1059-1069, (2017).

[5] K. Sritha,T. Rajaseenivasan,M. Arulmani. Energy recovery from a vapour compression refrigeration system using humidification dehumidification desalination. Desalination,439:155-161,(2018).

[6] Chen Wenbo. The research on solar desalination system with evacuated tube collectors. Dalian University of Technology,China, (2011).

[7] X.M.Zhang. Performance Analysis and Optimization Study on Heat, Water and Power Cogeneration System. Dalian University of Technology,China, (2009).

[8] X.Y.Gu. Research on integrated system of solar refrigeration and heating. Nanjing University of Technology,China, (2005).

[9] L.Y.Meng.The research on the absorption refrigerating/heat pump system combined solar and traditional energy in villas. Dalian University of Technology,China, (2005).

[10] Ge Weihuan, Guan Shu, Wang Dongping. Chemical process design and economy. Shanghai Science and Technology Publishing House, ,China, (1989).

[11] Ali M.El-Nashar. Economics of small solar-Assisted multiple-effect stack distillation plants. Desalination,

130:201-215,(2000).

[12] Bi Chanli.Study on the application of a parabolic trough linear concentrator solar absorption air conditioning system. Tianjin University,China, (2007).

[13] J. Liu , Z.W.Gao. Brief analysis of economic benefits of desalination. China Water Transport, 8(1): 209-211, (2008). 